\title{
Analysis Of Hotel Internet Booking Users
}

\author{
María-Encarnación Andrés-Martínez, University Of Castilla-La Mancha, Spain \\ Juan-Antonio Mondéjar-Jiménez, University Of Castilla-La Mancha, Spain \\ Miguel-Ángel Gómez-Borja, University Of Castilla-La Mancha, Spain \\ José-Luis Alfaro-Navarro, University Of Castilla-La Mancha, Spain
}

\begin{abstract}
The number of tourist products sold on the Internet has increased remarkably in recent years. The hotel industry has figured prominently in this boom due to hotel bookings made via the Internet becoming increasingly popular. The reason for this upturn in online bookings is, in many cases, the possibility of booking at any time and the possible existence of lower prices. In order to achieve these lower prices, consumers must accept certain restrictions or conditions that hotels use to manage demand through yield management strategies.

This paper analyses hotel Internet booking users in order to ascertain their socio-demographic characteristics and behaviour in regard to online purchase decisions. The ultimate goal is therefore to determine a user profile. With this information, hotel managers will be able to manage Internet hotel bookings.
\end{abstract}

Keywords: Internet; Hotel Booking; Socio-demographic; Consumer Profile

\section{INTRODUCTION}

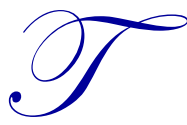

he emergence of the Internet as a means of communication and sales has led to a new understanding of the competitive exchange relationship in most marketplaces. In this sense, $76 \%$ of the European Union population in 2011 had used the Internet at least once, the number of Internet users being similar in the United States (78\%) and 66.3\% in Spain (ONTSI, 2012). Moreover, Internet continues to be an important source of news and general information, the search for information on health, general knowledge (i.e., consulting wikis such as Wikipedia), and travel and accommodations being one of the most popular services used by $54 \%$ of users.

The growing importance of virtual environments has influenced consumer decision-making processes which have become easier, faster and, in some cases, have improved as consumers can obtain more information, use tools to compare that information, and choose between different options directly and quickly.

The Internet is defined as an information office, as well as a huge interactive shop where people can purchase goods and services. Just how much importance is given to the Internet depends on the type of product or service being marketed. In this sense, industries such as leisure, clothing and electronics consider the Internet their priority sales channel (Ordozgoiti et al., 2010).

Authors, such as Gerbert et al. (1999), say that online purchases are the future of shopping, which is why researchers need to analyse online purchasing behaviour. In this sense, online research implies both cultural and technological change, which influences the way market research is conducted. Yu (2008) states that the Internet has revolutionised sales channels, changed the way that companies do business, and that an increasing number of people are opting to use that channel for their purchases. Notwithstanding, many consumers remain reluctant to shop online. More specifically, the B2C (Business-to-Consumer) e-Commerce Study for 2011 reported that only 50.7\% of Spanish Internet users make purchases online (ONTSI, 2012), a percentage similar to that in the European union as a whole, where $43 \%$ of the population aged 16 to 74 years used e-commerce in the last twelve months in 2011 (European Commission, 2012). 
Taking all of the above discussion into account, it is worth highlighting the main reasons justifying research into consumer behaviour in virtual environments, which are provided below (Mondéjar, 2006):

- $\quad$ Firstly, the spread of new information technologies, particularly those which provide access to artificial and global information environments, has seen this phenomenon become increasingly present in our lives, not only as a means to access information and perform commercial transactions, but also as a product and item of consumption in itself and as a means of information, entertainment and leisure.

- The potential of such environments to represent markets is ever increasing and commercial transactions can be carried out inside, or through them, using electronic mail tools as a basis. The features of this new scenario of exchanges between consumers and companies make analysing and understanding the characteristics that set apart consumer behaviour processes in these environments an enormously interesting topic.

- New technologies and virtual environments and the behaviours they generate, together with their characteristics and possibilities, which introduce the technologies that provide support to these markets, imply new needs, forms and methods of market research, in general, and consumers, in particular, that are vital to know.

With regard to the decision-making scenario, this research focuses on the tourism industry due to its sizeable share of total gross domestic product, which was estimated at $3 \%$ in 2012 by the World Travel \& Tourism Council (http://www.wttc.org/) and to the prominent role it will play in improving the current economic situation.

The importance of this industry can be clearly observed in online purchases as the activities linked to tourism, such as the purchase of transport tickets (flights, trains journeys...) and hotel bookings, among others, are considered one of the most important products of all online acquisitions. Thus, the Digital Agenda for Europe Scoreboard 2012 established that travel and holiday accommodations and clothes and sporting goods represented $52 \%$ of goods or services ordered over the Internet for private use in the last twelve months. This percentage is similar in Spain where the ONTSI (2012) has published further data confirming that transport tickets and hotel bookings, representing $49.5 \%$ and $39 \%$ of all acquisitions online, respectively, are indeed the star products of ecommerce. In the same line, the INE (2012) shows that accommodations and travel have been the services most acquired on the Internet in recent months (October 2011- October 2012), accounting for $54.6 \%$ and $49.7 \%$ of the total, respectively.

The arguments above clearly show that the tourism industry is gaining an increasingly significant presence on the Internet and, therefore, it is necessary to learn more about the profile of Internet consumers and, more specifically, the consumers of one of the most popular services on the Internet - hotel bookings. Subsequent sections describe the profile of hotel Internet booking users from a socio-demographic perspective, followed by the main aspects related to the purchase behaviour of these users and, finally, the main conclusions drawn from this research.

\section{SOCIO-DEMOGRAPHIC PROFILE OF HOTEL INTERNET BOOKING USERS}

In order to obtain information to determine the socio-demographic profile of hotel Internet booking users in Spain, the authors have developed a simulated context to attain the sample information. Internet users respond to four blocks of questions after participating in a simulated hotel online booking process. The first block of questions includes matters relating to demographic data (age and gender) and aspects, such as experience in booking accommodation online, in order to ascertain their booking habits and knowledge of prices. Respondents answer the second and third blocks of questions after booking a hotel online. These blocks include questions regarding perceived fairness and future purchase intentions. Finally, the fourth block includes socio-demographic questions (marital status, employment status, level of education, region and level of income). We use the first block of questions to divide the sample into two segments - one sample of users of hotel Internet bookings and another of non-users. The other blocks of questions are aimed at determining a user profile based on socio-demographic aspects and their purchase behaviour.

The study was undertaken by means of an online self-administered survey carried out between February 29 , 2012, and March 27, 2012, by 600 users, although the final number of valid questionnaires was 541; so the error 
margin is $\pm 4 \%$ at a significance level of $95 \%$. Sample selection was performed considering quotas based on the socio-demographic profile of Internet users between 16 and 74 years of age who sometimes purchase goods and services on the Internet.

Table 1 shows the contingency tables for Users of Hotel Internet Bookings (UHIB) and Non-Users of Hotel Internet Bookings (NUHIB) as well as for different socio-demographic variables such as gender, marital status, age, employment status, level of education, region, and level of income.

Table 1: Chi-Square Test Of Independence For Socio-Demographic Characteristics Versus UHIB

\begin{tabular}{|c|c|c|c|c|c|}
\hline & & NHIBU & HIBU & Chi-square & p-value \\
\hline \multirow{2}{*}{ Gender } & Man & $44.4 \%$ & $56.4 \%$ & \multirow{2}{*}{4.933} & \multirow{2}{*}{0.031} \\
\hline & Woman & $55.6 \%$ & $43.6 \%$ & & \\
\hline \multirow{5}{*}{ Marital Status } & Unmarried & $30.5 \%$ & $16.9 \%$ & \multirow{5}{*}{18.665} & \multirow{5}{*}{0.001} \\
\hline & Living with partner & $13 \%$ & $20.5 \%$ & & \\
\hline & Married & $51.9 \%$ & $57.3 \%$ & & \\
\hline & Separated-divorced & $0.9 \%$ & $4.4 \%$ & & \\
\hline & Widower & $3.7 \%$ & $0.9 \%$ & & \\
\hline \multirow{6}{*}{ Age } & Between 16 and 24 years & $17.6 \%$ & $4.2 \%$ & \multirow{6}{*}{36.416} & \multirow{6}{*}{0.000} \\
\hline & Between 25 and 34 years & $18.5 \%$ & $28.4 \%$ & & \\
\hline & Between 35 and 44 years & $32.4 \%$ & $35.1 \%$ & & \\
\hline & Between 45 and 54 years & $21.3 \%$ & $19.9 \%$ & & \\
\hline & Between 55 and 64 years & $5.6 \%$ & $11.5 \%$ & & \\
\hline & Between 65 and 74 years & $4.6 \%$ & $0.9 \%$ & & \\
\hline \multirow{6}{*}{$\begin{array}{l}\text { Employment } \\
\text { Status }\end{array}$} & Working & $65.7 \%$ & $84.8 \%$ & \multirow{6}{*}{45.718} & \multirow{6}{*}{0.000} \\
\hline & Retired/pensioner/disabled & $3.7 \%$ & $4.4 \%$ & & \\
\hline & Unemployed, but worked previously & $6.6 \%$ & $6.4 \%$ & & \\
\hline & Unemployed and seeking first job & $0.9 \%$ & $0.2 \%$ & & \\
\hline & Student & $12.0 \%$ & $2.8 \%$ & & \\
\hline & Household chores & $11.1 \%$ & $1.4 \%$ & & \\
\hline \multirow{5}{*}{$\begin{array}{l}\text { Educational } \\
\text { Level }\end{array}$} & Primary education & $1.9 \%$ & $0.2 \%$ & \multirow{5}{*}{19.831} & \multirow{5}{*}{0.001} \\
\hline & First stage of secondary education & $5.6 \%$ & $4.4 \%$ & & \\
\hline & Second stage of secondary education & $34.2 \%$ & $22.9 \%$ & & \\
\hline & Vocational training & $20.3 \%$ & $12.7 \%$ & & \\
\hline & Higher education & $38.0 \%$ & $59.8 \%$ & & \\
\hline \multirow{17}{*}{ Region } & Andalusia & $21.3 \%$ & $11.8 \%$ & \multirow{17}{*}{26.290} & \multirow{17}{*}{0.050} \\
\hline & Aragon & $1.9 \%$ & $3.9 \%$ & & \\
\hline & Asturias & $4.6 \%$ & $2.8 \%$ & & \\
\hline & Balearic Islands & $5.6 \%$ & $1.8 \%$ & & \\
\hline & Canary Islands & $2.8 \%$ & $1.6 \%$ & & \\
\hline & Cantabria & $1.9 \%$ & $0.5 \%$ & & \\
\hline & Castile and Leon & $2.8 \%$ & $6.2 \%$ & & \\
\hline & Castile-La Mancha & $1.9 \%$ & $3.7 \%$ & & \\
\hline & Catalonia & $10.2 \%$ & $20.8 \%$ & & \\
\hline & Region of Valencia & $11.1 \%$ & $9.2 \%$ & & \\
\hline & Extremadura & $1.8 \%$ & $0.7 \%$ & & \\
\hline & Galicia & $4.5 \%$ & $6.2 \%$ & & \\
\hline & Madrid & $22.2 \%$ & $21.2 \%$ & & \\
\hline & Murcia & $1.9 \%$ & $2.1 \%$ & & \\
\hline & Navarra & $0.9 \%$ & $1.3 \%$ & & \\
\hline & Basque Country & $4.6 \%$ & $5.3 \%$ & & \\
\hline & La Rioja & $0 \%$ & $0.9 \%$ & & \\
\hline \multirow{4}{*}{ Income Level } & Less than 1,100 euros & $27.8 \%$ & $9.7 \%$ & \multirow{4}{*}{25.633} & \multirow{4}{*}{0.000} \\
\hline & Between 1,100 and 1,800 euros & $28.7 \%$ & $29.8 \%$ & & \\
\hline & Between 1,801 and 2,700 euros & $26.9 \%$ & $37.6 \%$ & & \\
\hline & More than 2,700 euros & $16.6 \%$ & $22.9 \%$ & & \\
\hline
\end{tabular}

Source: Own Elaboration 
The results reveal a significant relationship between gender and being a user, such that $56.4 \%$ of men are UHIB, while $55.6 \%$ of women are NUHIB. There is also a relationship between marital status and whether or not a person is a UHIB. It is worth noting that 57.3\% of the UHIB and 51.9\% of NUHIB are married. In addition, 30.6\% of NUHIB are unmarried, while $20.6 \%$ of UHIB are living with a partner. In relation to the age of UHIB, $35.1 \%$ are between 35 and 44 years old, while 53.7\% of NUHIB are between 35 and 54 years of age. Furthermore, it is worth highlighting that there is a low percentage of NUHIB and HIBU aged between 65 and 74 years $(4.6 \%$ and $0.9 \%$, respectively). This is logical as these users are not so familiar with making hotel bookings online.

The results in Table 1 also show that there is a relationship between employment situation and being a UHIB. It is worth highlighting that $84.8 \%$ of UHIB are working, while $12 \%$ and $11.1 \%$ of NUHIB are students or engaged in household chores, respectively. This situation is logical because people that are working have less time to go to travel agencies and thus use the Internet more for their purchases. The results also confirm the relationship between the level of education and being a UHIB. In fact, 59.8\% of UHIB have completed higher education studies, while the percentage of NUHIB is higher in other categories. There is also a relationship between UHIB and region they live in. The highest percentage of NUHIB and UHIB are from Madrid, with $22.2 \%$ and $21.2 \%$, respectively. Note that the second highest percentage of UHIB is registered by Catalonia with 20.8\%, while the second highest percentage of NUHIB corresponds to Andalusia (21.3\%); that is, the largest regions with the most inhabitants have more online hotel booking users. The reason for this, despite these regions having more services than other regions, is probably because transport costs and transit time in those regions are higher, leading consumers to purchase online.

Finally, in relation to the level of income, the relationship is also significant and $37.6 \%$ of the UHIB are inside the income bracket ranging from 1,801 to 2,700 euros. In contrast, $27.8 \%$ of NUHIB earn less than 1,100 euros. Therefore, people with higher incomes use online hotel bookings more, maybe because they book hotels more often.

In summary, married men between the ages of 35 and 44 and who are working have university studies and earn a monthly income of between 1,801 and 2,700 euros, accounting for the largest percentage of UHIB. Most NUHIB are from Madrid (22.2\%).

\section{PURCHASE DECISION BEHAVIOR OF USERS OF HOTEL INTERNET BOOKINGS}

An analysis of the profile of hotel users revealed that most have, at some stage, booked a hotel on the Internet. With regard to the bookings made, it is worth noting that the last one made took place less than three months ago, which means that users have an up-to-date knowledge of the strategies used by hotels for online bookings and that the duration of the last booking was between one and three nights.

In the first place, the authors considered different kinds of rates in the hotel booking simulation conducted to gather sample information depending on whether or not hotels employed revenue management strategies. Moreover, if hotels do use revenue management strategies, the authors have distinguished between rates when the revenue management strategy implies an increase in price and when it entails a decrease. Thus, Table 2 shows the results of the chi-square test of independence considering these situations together with the user's condition. In regard to the rate selected, it is worth highlighting that UHIB prefer rates under revenue management strategies (59.1\%), while the NUHIB make their bookings by selecting hotels that do not use revenue management strategies (51.9\%). One possible reason may be that users are more familiar with this strategy, which is common on the Internet. In regard to the consequences of the strategy, differences are not statistically significant, although more UHIB (50.8\%) select strategies that imply a decrease in price, while $44.4 \%$ of NUHIB consider hotels that do not use revenue management strategies. The election of the revenue management strategies that involve a decrease in price in exchange for the consumer accepting certain restrictions (e.g. no changes in bookings) can be justified by the more familiarity of UHIB with this strategy. 
Table 2: Chi-Square Test Of Independence For Rate Selected Versus UHIB

\begin{tabular}{|c|c|c|c|c|c|}
\hline & & NUHIB & UHIB & Chi-square & p-value \\
\hline \multirow{2}{*}{ Rate Selected } & Revenue management strategy & $48.1 \%$ & $59.1 \%$ & \multirow{2}{*}{4.246} & \multirow{2}{*}{0.050} \\
\hline & No revenue management strategy & $51.9 \%$ & $40.9 \%$ & & \\
\hline \multirow{3}{*}{$\begin{array}{l}\text { Strategy } \\
\text { Consequences }\end{array}$} & Decrease & $38.9 \%$ & $50.8 \%$ & \multirow{3}{*}{4.979} & \multirow{3}{*}{0.083} \\
\hline & Increase & $16.7 \%$ & $12.7 \%$ & & \\
\hline & No revenue management & $44.4 \%$ & $36.5 \%$ & & \\
\hline
\end{tabular}

Source: Own elaboration

Other factors that could be related to purchase behaviour include Total Browsing Time (TBT), the maximum price per night that users would be willing to pay (PPN1), a reasonable price per night that users would be willing to pay (PPN2), the minimum price per night that users consider acceptable (PPN3), and General Price Knowledge (GPK). In order to verify whether there are significant differences between these factors and the user condition (UHIB versus NUHIB), the authors have developed an analyses of variance (ANOVA) using UHIB as the independent variable. The results show that there are significant differences in the mean in all cases, except for total browsing time. Tests cannot be performed post hoc because there are less than three groups. For this reason, averages have been calculated.

Table 3: ANOVA: UHIB

\begin{tabular}{|l|c|c|c|c|c|}
\hline \multirow{2}{*}{ Factor } & \multirow{2}{*}{ Dependence } & \multirow{2}{*}{ Levene } & \multirow{2}{*}{ Statistic } & \multicolumn{2}{|c|}{ Mean } \\
\cline { 3 - 6 } & TBT & 3.943 & $1.869^{\text {n.s. }}(\mathrm{F})$ & 161.81 & 132.19 \\
\cline { 2 - 6 } & PPN1 & 0.016 & $7.479 *(\mathrm{~F})$ & 96.79 & 82.93 \\
\cline { 2 - 6 } & PPN2 & 0.511 & $12.922 * *(\mathrm{~F})$ & 71.73 & 59.86 \\
\cline { 2 - 6 } & PPN3 & 0.628 & $5.847 *(\mathrm{~F})$ & 46.06 & 40.33 \\
\cline { 2 - 6 } & GPK & 18.118 & $64.265 * *(\mathrm{~W})$ & 5.808 & 4.417 \\
\hline
\end{tabular}

Note: $*$ and $* *$ statistically significant at $5 \%$ and $1 \%$, respectively. Parentheses in the statistics value show the statistics used for the ANOVA (Welch or F) based on the contrast of variance homogeneity performed with Levene's statistic.

The results show that hotel Internet booking users spend more time browsing the Internet when they book a hotel than non-users. This may be due to the fact that UHIB know that searching and comparing prices can lead them to a good price, although the difference in the time spent is not statistically significant. In regard to the reference price (PPN1, PPN2 and PPN3) of UHIB, it should be noted that their maximum, minimum and reasonable prices are higher than those who are NUHIB. Finally, UHIB have more general price knowledge because they can easily perform a search and comparison of prices which helps to increase their knowledge about hotel prices in general.

\section{CONCLUSIONS}

The results of this paper are of great interest to managers of hotels, as they can learn more about the sociodemographic characteristics and purchase behaviour of people that book their hotels, differentiating between those that use Internet to make bookings and the people that do not use the virtual channel.

An analysis of the profile of hotel booking users revealed that most have, at some stage, booked a hotel on the Internet. In regard to the socio-demographic profile of hotel booking users, most Internet hotel booking users are found to be male, married, have a high level of education, are working, and are high income earners. Furthermore, it is worth noting that the main place of origin is Madrid.

Furthermore, in relation to the rate selected, it is worth highlighting that UHIB prefer revenue management strategies when making hotel bookings, while NUHIB select no revenue management strategies when they book their hotels. As indicated previously, this could be due to users being more familiar with these strategies, as they are becoming more widely used by an increasing number of industries. Moreover, the fact that this strategy is new in the hotel industry and has been implemented more frequently in recent years means that people who are not used to booking hotels on the Internet tend not to trust the offers and opt for a traditional booking, even if it is more expensive. 


\section{AUTHOR INFORMATION}

María-Encarnación Andrés-Martínez has a Ph.D. and Degree in Business Administration from the University of Castilla-La Mancha and is Assistant Professor in Marketing in the Business Administration Department, Faculty of Economics and Business Administration of Albacete at the University of Castilla-La Mancha (Spain). Her research interests include consumer behaviour, price perception, Internet and tourism.

E-mail: Encarnacion.Andres@uclm.es.

Juan-Antonio Mondéjar-Jiménez ha a Ph.D. and Degree in Business Administration from the University of Castilla-La Mancha and a Degree in Advanced Studies in Marketing at the same university. He is an Associate Professor in Marketing in the Business Department, Faculty of Social Sciences of Cuenca at the University of Castilla-La Mancha (Spain). His research interests include consumer behavior, price perception, e-learning and tourism marketing.

E-mail: JuanAntonio.Mondejar@uclm.es.

Miguel-Ángel Gómez-Borja has a B.S. in Business Administration, School of Economics from the University of Valencia (Spain) and a Ph.D. in Business and Economics from the University of Castilla-La Mancha (Spain). He is an Associate Professor of Marketing in the School of Economics and Business Administration at the University of Castilla-La Mancha, Albacete Campus (Spain). His research interests include consumer behavior, social media marketing, pricing, tourism marketing, ICT and marketing research, new technologies and retailing, international retailing, and non-profit marketing.

E-mail: miguelangel.gborja@uclm.es.

José-Luis Alfaro-Navarro has a Ph.D. in Economics and a Degree in Business Administration from the University of Castilla-La Mancha. He is an Assistant Professor in the Statistics Department, Faculty of Economics and Business Administration of Albacete at the University of Castilla-La Mancha (Spain). His research interests include statistical quality control, regional analysis, and agrarian prices.

E-mail: JoseLuis.Alfaro@uclm.es.

\section{REFERENCES}

1. European Commission. (2012). Digital Agenda for Europa. Available at: http://ec.europa.eu/digitalagenda/.

2. Gerbert, P., Schneider, D., and Birch, A. (1999). The age of e-tail: conquering the new world of electronic shopping. Milford, CT: Capstone.

3. INE. (2012): Encuesta sobre Equipamiento y Uso de Tecnologías de la Información y Comunicación en los hogares 2012. Available at: http://www.ine.es.

4. Mondéjar, J. A. (2006). Percepción de la dispersión de precios por el consumidor en entornos virtuales. Tesis doctoral. Universidad de Castilla-La Mancha.

5. ONTSI. (2012). "Estudio sobre Comercio Electrónico B2C 2011 (Edición 2012)”. Available at: http://www.ontsi.red.es/ontsi/.

6. $\quad$ Ordozgoiti, R., Rodríguez, D., Olmos, A.. and Miranda, J. A. (2010). Publicidad online las claves del éxito en Internet. Esic, Madrid.

7. Yu, S. F. (2008). "Price perception of online airline ticket shoppers". Journal of Air Transport Management, 14(2), 66-69. 